\title{
Article \\ Conflicting Nongenomic Effects of Progesterone in the Myometrium of Pregnant Rats
}

\author{
Katsuhiko Yasuda *, Aya Yoshida and Hidetaka Okada (D) \\ Department of Obstetrics and Gynecology, Kansai Medical University, 2-5-1 Shinmachi, Hirakata, \\ Osaka 573-1010, Japan; yoshiaya@hirakata.kmu.ac.jp (A.Y.); hokada@hirakata.kmu.ac.jp (H.O.) \\ * Correspondence: ksafety@yasuda-mf.or.jp; Tel.: +81-72-804-0101; Fax: +81-72-804-0122
}

Citation: Yasuda, K.; Yoshida, A.; Okada, H. Conflicting Nongenomic Effects of Progesterone in the Myometrium of Pregnant Rats. Int. J. Mol. Sci. 2021, 22, 2154.

https: / / doi.org/10.3390/ijms22042154

Academic Editor: Muriel Le Romancer

Received: 23 January 2021

Accepted: 19 February 2021

Published: 22 February 2021

Publisher's Note: MDPI stays neutral with regard to jurisdictional claims in published maps and institutional affiliations.

Copyright: (C) 2021 by the authors Licensee MDPI, Basel, Switzerland. This article is an open access article distributed under the terms and conditions of the Creative Commons Attribution (CC BY) license (https:/ / creativecommons.org/licenses/by/ $4.0 /)$.

\begin{abstract}
Recently, it has been suggested that progesterone affects the contractile activity of pregnant myometrium via nongenomic pathways; therefore, we aimed to clarify whether progesterone causes and/or inhibits pregnant myometrial contractions via nongenomic pathways. Our in vitro experiments using myometrial strips obtained from rats at 20 days of gestation revealed that progesterone caused myometrial contractions in a concentration- and time-dependent manner at concentrations up to $5 \times 10^{-7} \mathrm{M}$; however, this effect decreased at concentrations higher than $5 \times 10^{-5} \mathrm{M}$. Similarly, progesterone enhanced oxytocin-induced contractions up to $5 \times 10^{-7} \mathrm{M}$ and inhibited contractions at concentrations higher than $5 \times 10^{-5} \mathrm{M}$. Conversely, progesterone did not enhance high-KClinduced contractions but inhibited contractions in a concentration- and time-dependent manner at concentrations higher than $5 \times 10^{-7} \mathrm{M}$. We also found that RU486 did not affect progesteroneinduced contractions or the progesterone-induced inhibition of high-KCl-induced contractions; however, progesterone-induced contractions were blocked by calcium-free phosphate saline solution, verapamil, and nifedipine. In addition, FPL64176, an activator of L-type voltage-dependent calcium channels, enhanced high-KCl-induced contractions and rescued the decrease in high-KClinduced contractions caused by progesterone. Together, these results suggest that progesterone exerts conflicting nongenomic effects on the contractions of pregnant myometrium via putative L-type voltage-dependent calcium channels.
\end{abstract}

Keywords: conflicting nongenomic effects; pregnant myometrium; progesterone; voltage-dependent calcium channel

\section{Introduction}

Steroid hormones play many important roles in living organisms and are involved in various physiological processes, such as growth, development, anabolism, catabolism, and reproduction. The steroid hormones estrogen and progesterone are involved in reproductive organ growth and development, ovulation, fertilization, implantation, preservation of pregnancy, labor, and nursing. In the myometrium, estrogen plays an important role in increasing the uterine contractile response, whereas progesterone counteracts this effect [1-5]. Consequently, progesterone reduces the rate of preterm birth by inhibiting premature uterine contractions caused by uterotonic agents, including oxytocin or prostaglandin $\mathrm{F}_{2 \alpha}[6,7]$, and its use is recommended by published guidelines to prevent preterm birth [8-10].

During parturition, many factors, including oxytocin, prostaglandin, cytokines, proteases, calcium ion $\left(\mathrm{Ca}^{2+}\right)$ channels, and contractile proteins, are involved in labor pain and participate in a common pathway that affects myometrial contractions. In smooth muscles such as the myometrium, increased intracellular $\mathrm{Ca}^{2+}$ levels are required for contractions induced by factors, including oxytocin, prostaglandin, and mechanical stimuli, whereas voltage-dependent calcium channels (VDCCs) and receptor-operated calcium channels (ROCCs) play key roles in increasing intracellular $\mathrm{Ca}^{2+}$ levels during uterine contractions $[11,12]$. Previously, progesterone was thought to exert specific effects on target organs via genomic pathways through the nuclear progesterone receptor (nPR). More specifically, 
after combining with progesterone, nPRs undergo a conformational change and dimerization, leading to translocation to the nucleus where progesterone acts as a ligand-activated transcription factor. Progesterone/nPR complexes can also modulate the activities of Src tyrosine kinase and some mitogen-activated protein kinases (MAPKs) in the cytoplasm; the MAPKs are translocated to the nucleus, where they affect gene expression. Despite these genomic pathways, most recent evidence suggests that progesterone acts via nongenomic pathways [13-21].

Some steroid hormones, including androgen and progestins, have been shown to inhibit myometrial contractions in nonpregnant rats in a nongenomic manner [13-15]. We previously reported that dydrogesterone, a retroprogesterone derivative with a reversed three-dimensional structure, could nongenomically inhibit myometrial contractions in pregnant rats and pregnant women [16]. In addition, it has been suggested that progesterone inhibits the contractile activity of the vascular smooth muscle by decreasing the intracellular $\mathrm{Ca}^{2+}$ concentration via nongenomic pathways involving the membrane progesterone receptor (mPR)-inhibitory G protein [17]. However, progesterone/mPRs coupled with the inhibitory $G$ protein have been reported to decrease cAMP levels and increase myosin light-chain (MLC) phosphorylation to facilitate contractions in pregnant myometrium [18]. Similarly, progesterone exerts a nongenomic stimulatory effect on contractions in a pregnant myometrium [19-21]; however, the role of mPRs remains unclear.

Although progesterone's role in decreasing uterine contractions via genomic pathways has been studied extensively [22,23], few studies have investigated whether steroid hormones, including progesterone, affect the contractile activity of pregnant myometrium via nongenomic pathways. In this study, we examined the effects of steroid hormones on myometrial contractions via nongenomic pathways involving $\mathrm{Ca}^{2+}$ channels using myometrial strips prepared from the uterine tissues of pregnant rats.

\section{Results}

\subsection{Effects of Natural Steroid Hormones on Resting Myometrium}

First, we evaluated the possible stimulatory effects of steroid hormones, including progesterone, on the contractile activity of the resting myometrium. In nonpregnant women, the serum concentration of progesterone is known to be $10^{-7} \mathrm{M}$ in the secretory phase; however, this level increases to $10^{-6}-10^{-5} \mathrm{M}$ during pregnancy. In rats, the concentration of progesterone is reported to increase to $5 \times 10^{-7} \mathrm{M}$ during pregnancy [24]. We evaluated the effect of sequentially increasing progesterone levels in physiological saline solution (PSS; $>10^{-7} \mathrm{M}$ ) on the contractile activity by measuring the peak area of contraction, representing frequency, tension (amplitude), and contractile time (Figure S1A,B). The peak area of high-KCl-induced contractions was used as a reference, and the contractile activity was evaluated using the relative ratio of the peak area (RRPA; steroid hormone-induced peak area/high- $\mathrm{KCl}$-induced peak area) as the absolute values of the peak area varied largely between the myometrial strips obtained from different rats.

At a concentration of $5 \times 10^{-7} \mathrm{M}$, progesterone caused rhythmic myometrial contractions, and this effect increased in a concentration-dependent manner up to $5 \times 10^{-6} \mathrm{M}$ (Figure 1A); however, the tension appeared to decrease slightly at $10^{-5} \mathrm{M}$, whereas the contractions decreased considerably at $5 \times 10^{-5} \mathrm{M}$ and disappeared altogether at $10^{-4} \mathrm{M}$. Other steroid hormones, such as $17 \beta$-estradiol, testosterone, cortisol, and aldosterone, did not cause notable contractions. As shown in Figure 1B and Table S1, the RRPA in the progesterone group increased in a concentration-dependent manner from $5 \times 10^{-7} \mathrm{M}$ to $5 \times 10^{-6} \mathrm{M}$ and was still high at $10^{-5} \mathrm{M}$; however, the RRPA decreased at $5 \times 10^{-5} \mathrm{M}$ and became zero at $10^{-4} \mathrm{M}$. Significant increases were observed between the progesterone and vehicle groups at the various concentrations $(p<0.05)$, whereas no significant differences were found in the RRPA of the $17 \beta$-estradiol, testosterone, cortisol, and aldosterone groups $(n=6$, mean $\pm \mathrm{SD})$. 
Next, we examined the effects of progesterone on contractions when added in a single dose. As shown in Figure 1C, progesterone caused rhythmic contractions with a lag at a concentration of $5 \times 10^{-7} \mathrm{M}$; however, the lag disappeared, and contractions increased in a time-dependent manner at concentrations $>10^{-6} \mathrm{M}$ before decreasing gradually at concentrations $>10^{-5} \mathrm{M}$. At $5 \times 10^{-5} \mathrm{M}$ and $10^{-4} \mathrm{M}$, contractions occurred sporadically for five min and then disappeared $10 \mathrm{~min}$ after the addition. As shown in Figure 1D and Table S2, the RRPA increased in a time-dependent manner in the progesterone group $(n=6$; mean $\pm \mathrm{SD})$ at $5 \times 10^{-7} \mathrm{M}$. Conversely, the RRPA in the vehicle group $(n=6$, mean $\pm \mathrm{SD})$ was negligible (Table S2). A significant difference was observed between the progesterone and vehicle groups at 10-15 and 15-20 min. The significant and rapid increase in the RRPA of the progesterone group was more obvious at $10^{-6} \mathrm{M}$ and $5 \times 10^{-6} \mathrm{M}$, respectively. Moreover, the RRPA at $10^{-5} \mathrm{M}$ increased significantly during the first $10 \mathrm{~min}$ but decreased during the next $10 \mathrm{~min}$. The RRPA at $5 \times 10^{-5} \mathrm{M}$ and $10^{-4} \mathrm{M}$ increased rapidly and significantly at $0-5 \mathrm{~min}$ but decreased to low levels at 5-10 $\mathrm{min}$ and did not increase again. We found two contractile patterns depending on the concentration of progesterone, with a time-dependent increase observed at a low concentration and a transient increase at a high concentration.

\subsection{Effects of Progesterone on Oxytocin- and High-KCl-Induced Myometrial Contractions}

It has been reported that dydrogesterone inhibits oxytocin- and high-KCl-induced contractions via nongenomic pathways [14], and progesterone can inhibit oxytocin-induced contractions at the nanomolar level by interfering with the binding between oxytocin and its receptor [25]. We examined whether progesterone inhibited oxytocin- or high-KCl-induced contractions. Unexpectedly, we found that progesterone increased the contractile time of each peak in the oxytocin $(100 \mu \mathrm{unit} / \mathrm{mL})$-induced contractions up to a concentration of $5 \times 10^{-6} \mathrm{M}$ (Figure 2A), and the contractile time of each peak remained long at $10^{-5} \mathrm{M}$; the contractions were inhibited completely at $>5 \times 10^{-5} \mathrm{M}$. As shown in Figure $2 \mathrm{~B}$ and Table S3, the RRPA of oxytocin-induced contractions in the progesterone group was significantly higher than that in the vehicle group from $5 \times 10^{-7} \mathrm{M}$ to $10^{-5} \mathrm{M}$ and significantly lower at concentrations $>5 \times 10^{-5} \mathrm{M}(n=6$, mean $\pm \mathrm{SD})$.

Progesterone did not enhance the high-KCl-induced contractions but inhibited the contractions in a concentration-dependent manner at a concentration $>5 \times 10^{-7} \mathrm{M}$ and completely at the concentration $>5 \times 10^{-5} \mathrm{M}$ (Figure 2C). After the sixth medium exchange, the response to high $\mathrm{KCl}$ was recovered to previous levels; however, the vehicle did not affect the high-KCl-induced contraction, and the response to a high- $\mathrm{KCl}$ concentration was recovered immediately after the exchange. The RRPA of the high-KCl-induced contractions was significantly lower in the progesterone group $(n=6$, mean $\pm \mathrm{SD})$ than in the vehicle group $(n=6$, mean $\pm \mathrm{SD})$ at the concentration $>5 \times 10^{-7} \mathrm{M}$ (Figure 2D and Table S3) and decreased in a concentration-dependent manner. 


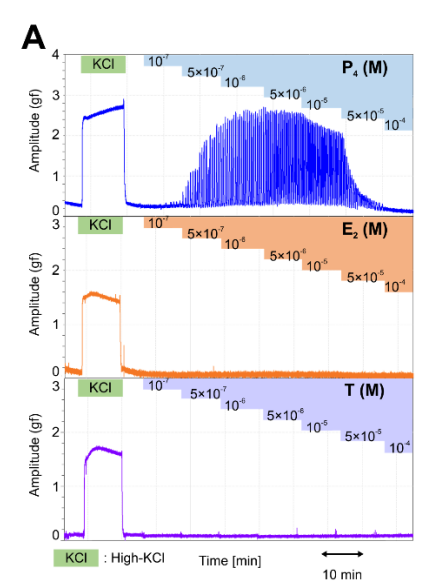

B

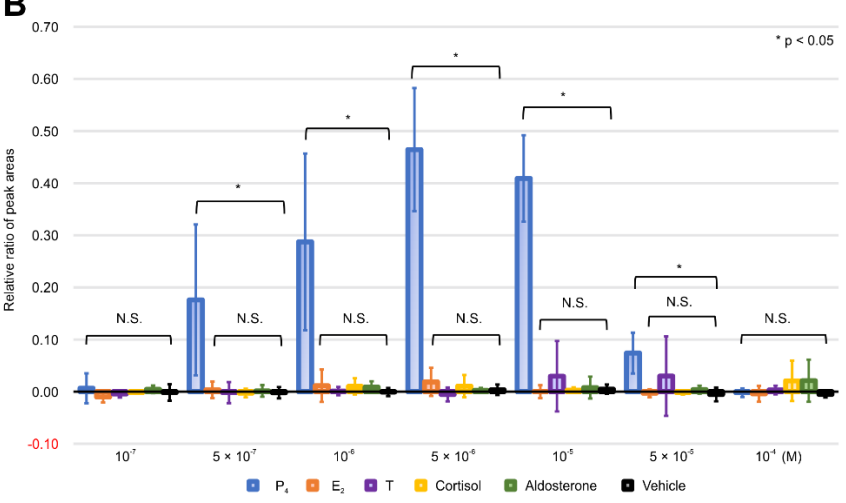

C
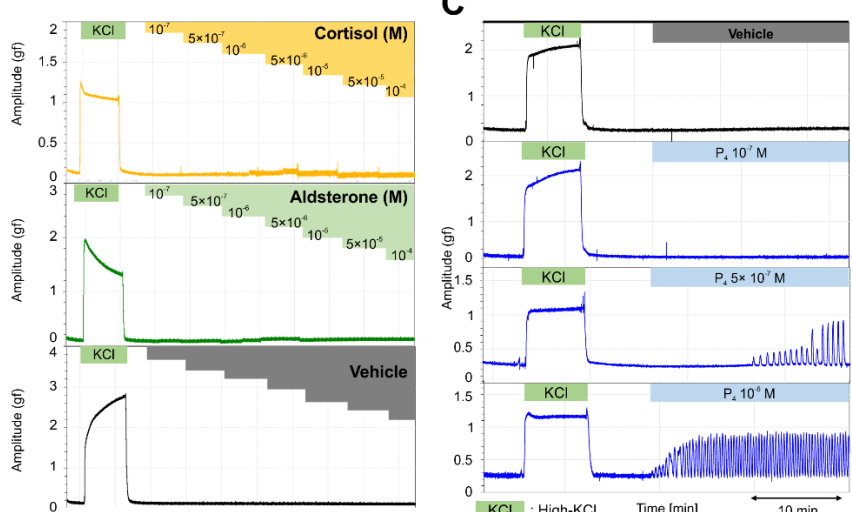

D

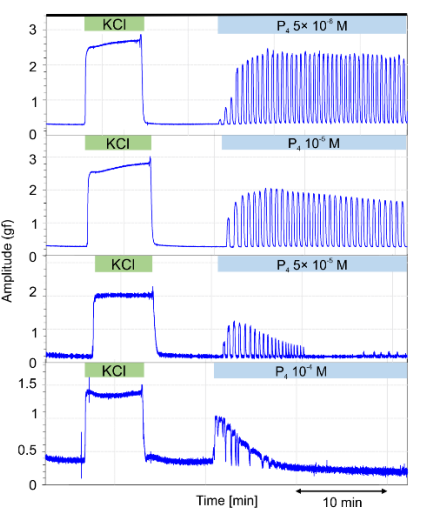

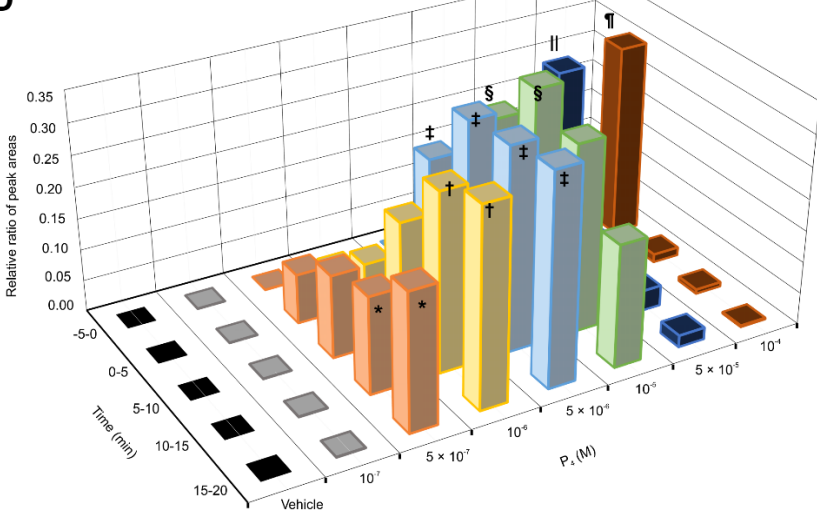

Figure 1. Effects of various natural steroid hormones on the contractile activities in the resting myometrium. (A) Representative myograph of six myographs obtained from experiments that used myometrial strips prepared from the uterine tissues of rats at 20 days of gestation. Progesterone $\left(\mathrm{P}_{4}\right), 17 \beta$-estradiol $\left(\mathrm{E}_{2}\right)$, testosterone (T), cortisol, and aldosterone were added sequentially to a physiological saline solution (PSS) at concentrations of $10^{-7} \mathrm{M}-10^{-4} \mathrm{M}$. (B) The relative ratio of the peak area (RRPA) of the progesterone $\left(\mathrm{P}_{4}\right), 17 \beta$-estradiol $\left(\mathrm{E}_{2}\right)$, testosterone $(\mathrm{T})$, cortisol, aldosterone, and vehicle groups in the resting myometrium. The peak area of high-KCl-induced contractions for $10 \mathrm{~min}$ was defined as the reference area. (C) Representative myograph of six myographs obtained from experiments that evaluated the effects of single-dose progesterone on the contractile activities in the resting myometrium. Progesterone was added to the PSS at the concentrations of $10^{-7}-10^{-4}$ M. (D) Time- and concentration-dependent changes in the RRPA of the vehicle and progesterone groups at various progesterone concentrations. The peak area of high-KCl-induced contractions for 5 min was defined as the reference area. ${ }^{*} p<0.05,{ }^{\dagger} p<0.05,{ }^{\ddagger} p<0.05,{ }^{\S} p<0.05, \|^{*} p<0.05,{ }^{\mathbb{T}} p<0.05$. 
A

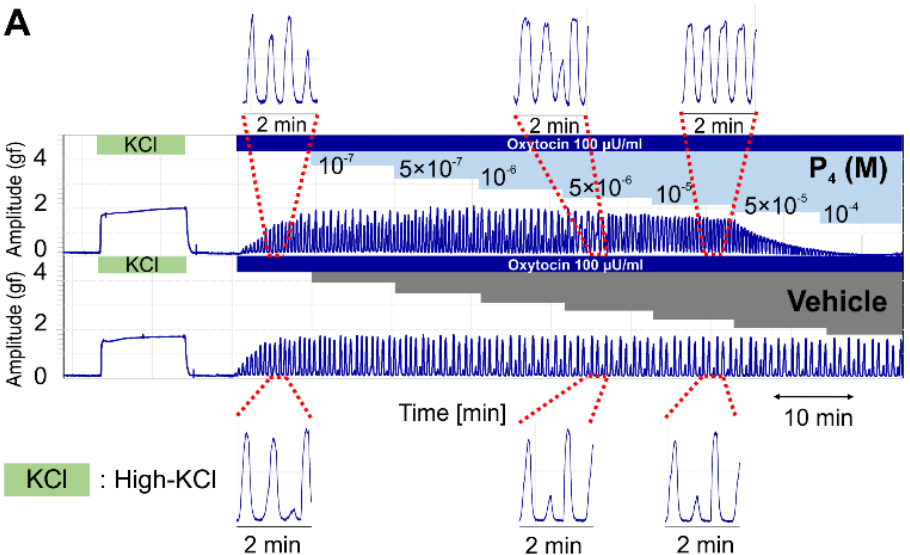

B

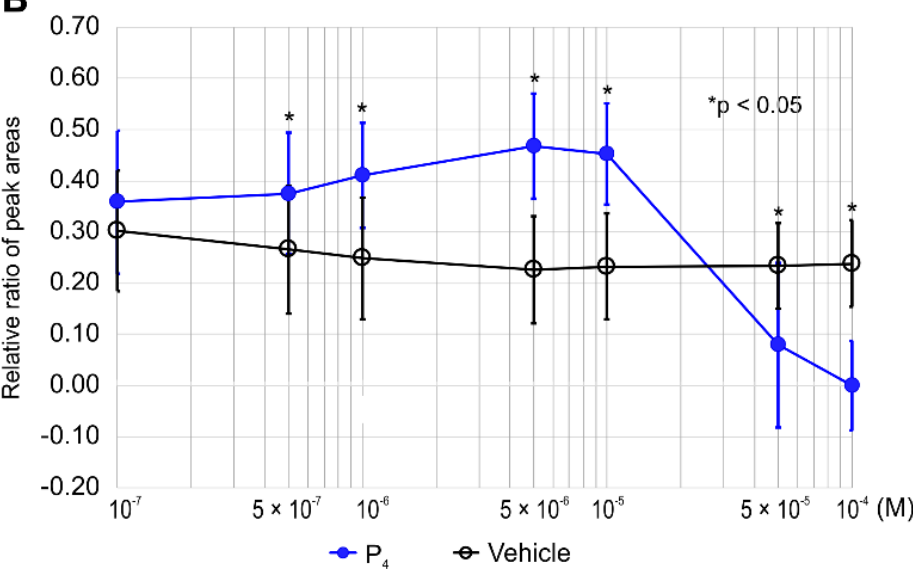

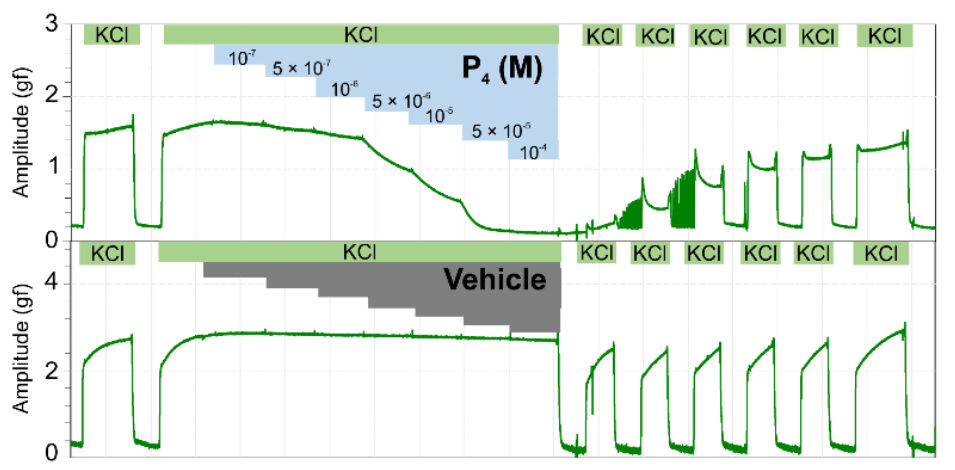

Time [min]

$\overleftrightarrow{\longleftrightarrow \text { min }}$

D

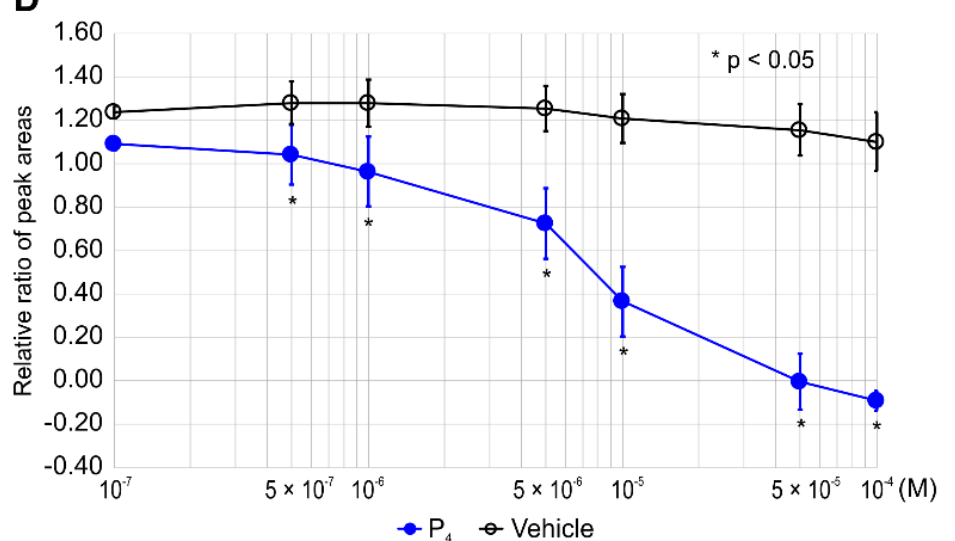

Figure 2. Effects of progesterone on oxytocin- and high-KCl-induced contractions. (A) Representative myograph of six myographs obtained when rhythmic contractions were induced by oxytocin $(100 \mu \mathrm{unit} / \mathrm{mL})$, and progesterone was sequentially added to a physiological saline solution (PSS) at the concentration of $10^{-7} \mathrm{M}-10^{-4} \mathrm{M}$ every $10 \mathrm{~min}$ after a contraction. (B) Time-dependent changes in the relative ratio of the peak area (RRPA) of oxytocin-induced contractions in the progesterone and vehicle groups. (C) Representative myograph of six myographs obtained when tonic contractions were induced by high $\mathrm{KCl}(72.7 \mathrm{mM})$, and progesterone was sequentially added into the PSS at the concentrations of $10^{-7} \mathrm{M}-10^{-4} \mathrm{M}$ every $10 \mathrm{~min}$ after a contraction. (D) Time-dependent changes in the RRPA of high-KCl-induced contractions in the progesterone and vehicle groups. 


\subsection{RU486 Does Not Alter the Effects of Progesterone on Contractile Activity}

To confirm whether the effects of progesterone were independent of genomic pathways involving nPR, we examined whether a pretreatment with RU486, a progesterone antagonist for $\mathrm{nPR}$, for $60 \mathrm{~min}$ blocked the effect of progesterone on contractile activity in the resting myometrium and during high-KCl-induced contractions. Interestingly, a RU486 pretreatment did not inhibit rapid progesterone $\left(5 \times 10^{-6} \mathrm{M}\right)$-induced contractions, early progesterone $\left(5 \times 10^{-5} \mathrm{M}\right)$-induced contractions, or the subsequent contraction inhibitions (Figure 3A). As shown in Figure 3B and Table S4, the RRPAs of the progesterone $\left(5 \times 10^{-6} \mathrm{M}\right)$-induced contractions were not significantly different between the vehicle $(n=6$, mean $\pm \mathrm{SD})$ and RU486 $(n=6$, mean $\pm \mathrm{SD})$ pretreatment groups. Similarly, the RRPAs of the progesterone $\left(5 \times 10^{-5} \mathrm{M}\right)$-induced contractions were not significantly different between the vehicle $(n=6$, mean $\pm \mathrm{SD})$ and RU486 $(n=6$, mean \pm SD) pretreatment groups. The inhibitory effect of progesterone $\left(5 \times 10^{-6} \mathrm{M}\right)$ on the high-KCl-induced contractions was not blocked by the RU486 pretreatment for $60 \mathrm{~min}\left(5 \times 10^{-7} \mathrm{M}\right.$; Figure 3C). As shown in Figure 3D and Table S4, the RRPAs of high-KCl-induced contractions were not different between the vehicle $(n=6$, mean $\pm \mathrm{SD})$ and $\mathrm{RU} 486(n=6$, mean $\pm \mathrm{SD})$ pretreatment groups. Thus, RU486 did not affect progesterone-induced contractions in the resting myometrium or the progesterone-induced inhibition of high-KCl-induced myometrial contractions.

2.4. Calcium-Free PSS and VDCC Inhibitors Alter the Stimulatory Effect of Progesterone in the Resting Myometrium, Whereas FPL64176 Alters the Inhibitory Effect of Progesterone on High-KCl-Induced Myometrial Contractions

VDCCs are known to play important roles in increasing intracellular $\mathrm{Ca}^{2+}$ levels, which are required for myometrial contractions. L-type calcium channels are an important type of VDCC, which also includes N-, P/Q-, R-, and T-type channels. We investigated the role of calcium influx in the stimulation of the resting myometrium by progesterone using calcium-free PSS, verapamil (a VDCC inhibitor), and nifedipine (an L-type VDCC inhibitor). Interestingly, progesterone $\left(5 \times 10^{-6} \mathrm{M}\right)$ did not cause rhythmic contractions in calcium-free PSS (Figure 4A). As shown in Figure 4B and Table S5, the RRPA in the progesterone group increased in the presence of PSS $(n=6$, mean \pm SD); however, it reached a value of zero at every five-min interval in the presence of calcium-free PSS. Significant differences were observed at every five-min interval between the two groups. As shown in Figure $4 \mathrm{C}$, a 15-min pretreatment with nifedipine $\left(10^{-7} \mathrm{M}\right)$ and verapamil $\left(5 \times 10^{-7} \mathrm{M}\right)$ completely inhibited progesterone $\left(5 \times 10^{-6} \mathrm{M}\right)$-induced contractions, unlike that with the vehicle. As shown in Figure 4D and Table S5, the RRPAs in the vehicle pretreatment group $(n=6$, mean $\pm \mathrm{SD})$ increased in a time-dependent manner and were significantly greater than those in both the nifedipine and verapamil pretreatment groups $(n=6$, mean $\pm \mathrm{SD})$ at every five-min interval.

Finally, we examined whether FPL64176, an activator of L-type VDCCs [26,27], influenced the inhibitory effects of progesterone on high-KCl-induced contractions. As shown in Figure 4E, high-KCl-induced contractions decreased for $20 \mathrm{~min}$ after the addition of progesterone $\left(5 \times 10^{-6} \mathrm{M}\right)$, increased after the addition of FPL64176 $\left(10^{-7} \mathrm{M}\right)$, and returned to previous levels $20 \mathrm{~min}$ later but continued to decrease $20 \mathrm{~min}$ after the vehicle was added. High- $\mathrm{KCl}$-induced contractions did not change for $40 \mathrm{~min}$ following the addition of the vehicle alone; however, FPL64276 increased the contractions for $40 \mathrm{~min}$. As shown in Figure $4 \mathrm{~F}$ and Table $\mathrm{S} 6$, the RRPAs of high- $\mathrm{KCl}$-induced contractions in the progesterone + FPL64176 group ( $n=6$, mean $\pm \mathrm{SD}$ ) returned to the previous levels after 30-35 min (10-15 min after the addition of FPL631476) and 35-40 $\mathrm{min}$ (15-20 min after the addition of FPL64176), whereas the RRPAs of high-KCl-induced contractions in the progesterone + vehicle groups $(n=6$, mean $\pm \mathrm{SD})$ still decreased after the addition of the vehicle. Significant differences were observed between the two groups at 20-25, 25-30, 30-35, and 35-40 min. The RRPAs of high-KCl-induced contractions in the FPL64176-only group $(n=6$, mean $\pm \mathrm{SD})$ increased in a time-dependent manner for $40 \mathrm{~min}$, whereas the RRPAs of high- $\mathrm{KCl}$-induced contractions in the vehicle-only groups $(n=6$, mean $\pm \mathrm{SD})$ were 
stable for $40 \mathrm{~min}$ (Figure 4F and Table S6). Significant differences were observed between the two groups at five-min intervals after FPL64176 was added. FPL64176 enhanced the high-KCl-induced contractions via L-type VDCC, and the recovered high-KCl-induced contractions decreased by progesterone via the L-type VDCC.

A

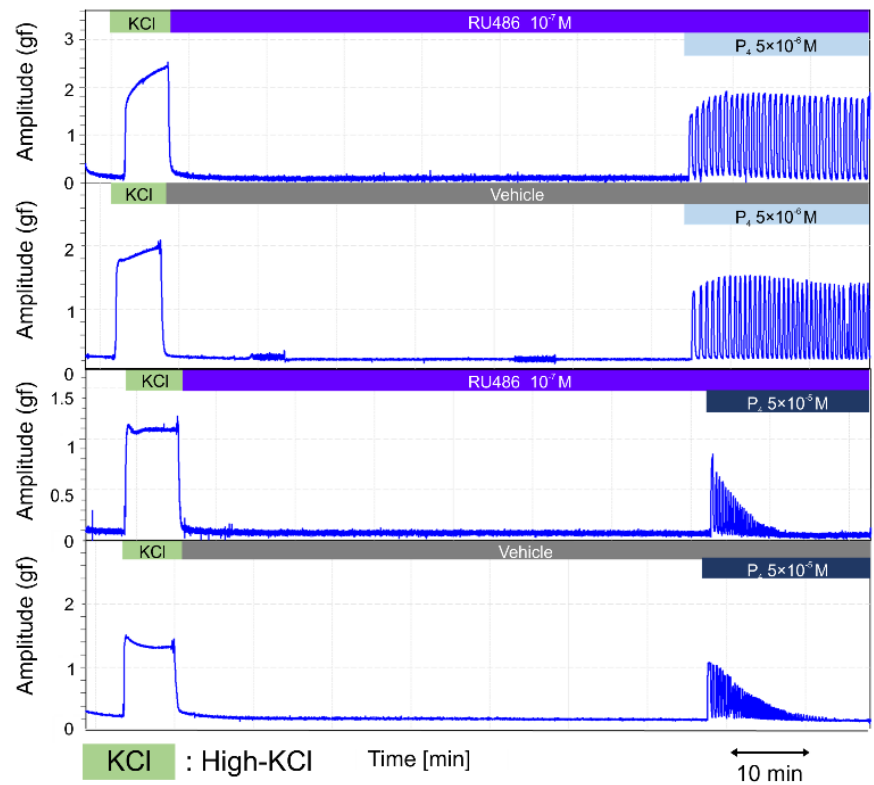

B
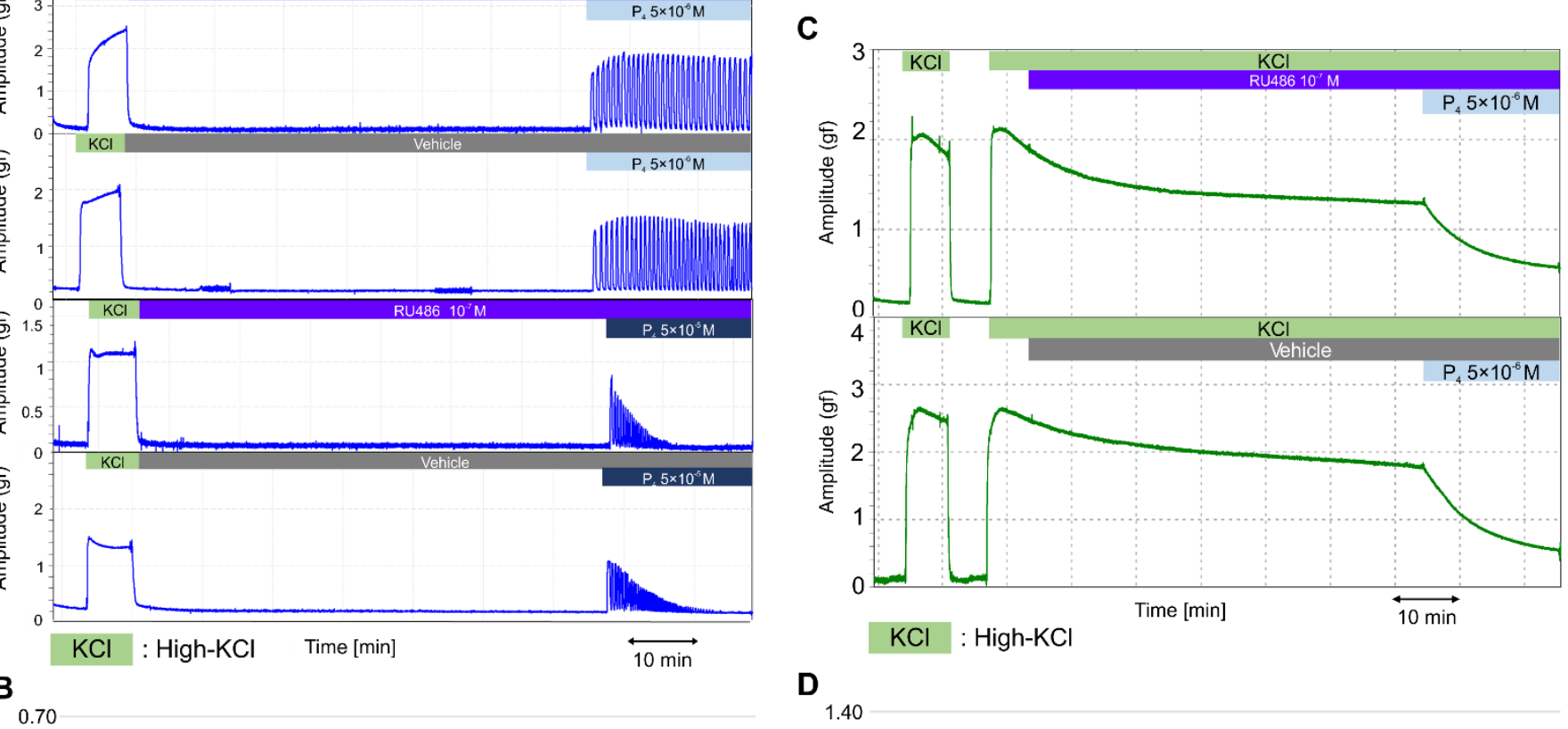

D
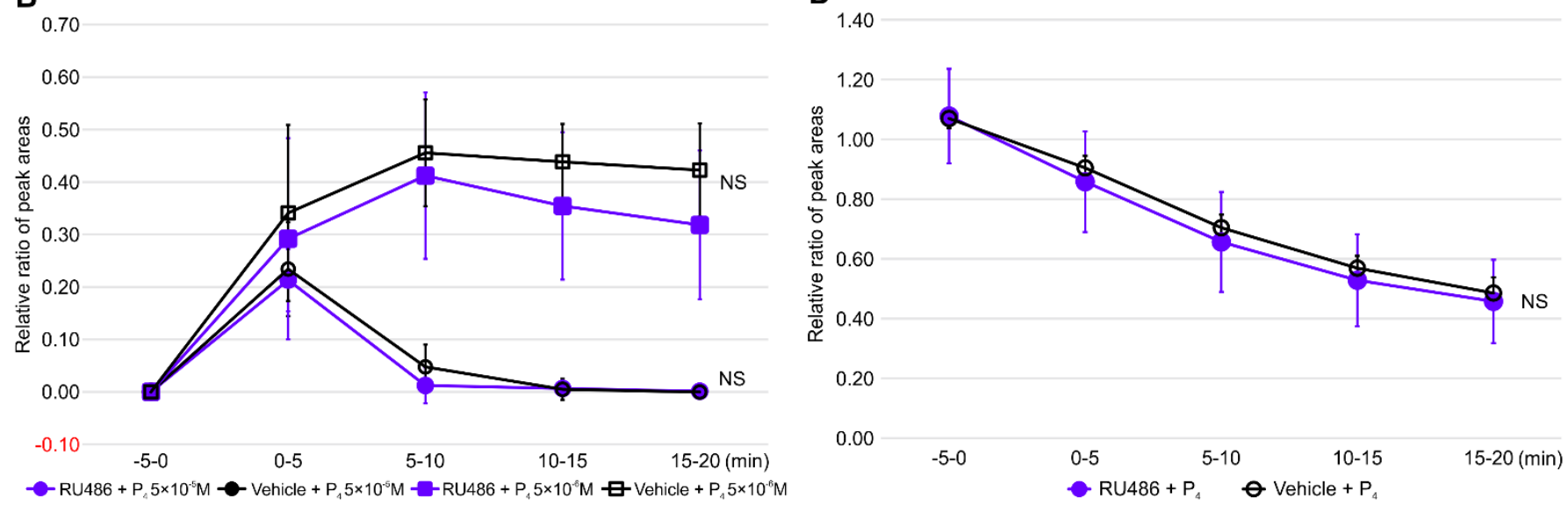

Figure 3. Effects of RU486 on progesterone-induced contractions in the resting myometrium and on progesterone-induced inhibitions against high-KCl-induced contractions. (A) Representative myograph of six myographs was obtained when the resting myometrial strips were pretreated with RU486 $\left(10^{-7} \mathrm{M}\right)$ or a vehicle for 60 min, progesterone was added at $5 \times 10^{-6}$ or $5 \times 10^{-5} \mathrm{M}$, and myometrial strips were cotreated with RU486 or a vehicle for $20 \mathrm{~min}$. (B) Time-dependent changes in the relative ratio of the peak area (RRPA) of progesterone-induced contractions in the RU486- and vehicle-treated groups. (C) Representative myograph of six myographs obtained when myometrial strips contracted by high $\mathrm{KCl}$ were pretreated with RU486 or a vehicle for $60 \mathrm{~min}$, progesterone was added at $5 \times 10^{-6} \mathrm{M}$, and the strips were cotreated with RU486 or a vehicle for $20 \mathrm{~min}$. (D) Time-dependent changes in the RRPA of high-KCl-induced contractions in the RU486and vehicle-treated progesterone groups. 

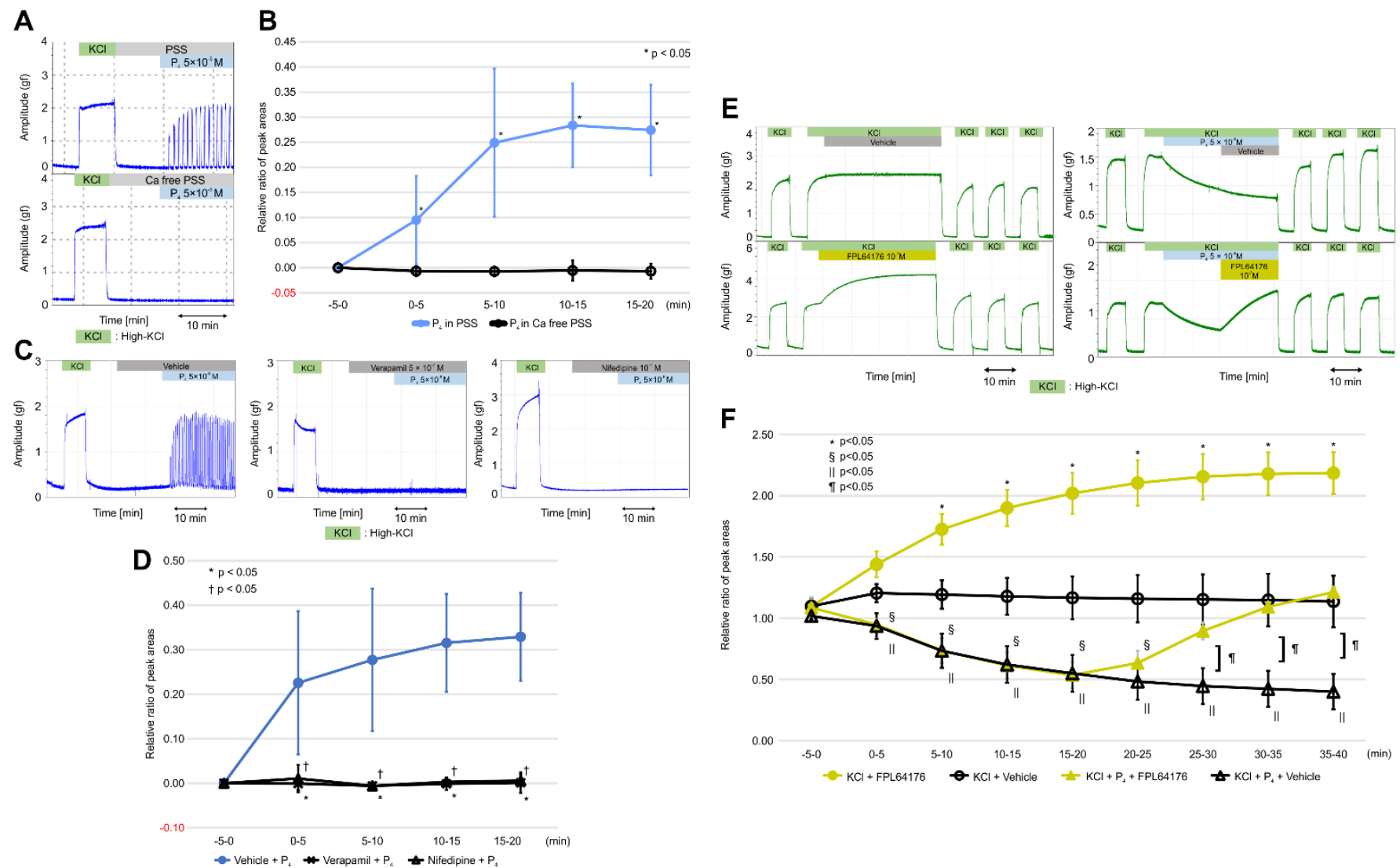

Figure 4. Effects of calcium-free physiological saline solution (PSS), verapamil, and nifedipine on progesterone-induced contractions in the resting myometrium, and the effect of FPL64176 on progesterone-induced inhibition against high$\mathrm{KCl}$-induced contractions. (A) Representative myograph of six myographs obtained when progesterone $\left(5 \times 10^{-6} \mathrm{M}\right)$ was added into calcium-free PSS and PSS. (B) Time-dependent changes in the relative ratio of the peak area (RRPA) of progesterone-induced contractions in calcium-free PSS and PSS. (C) Effects of verapamil and nifedipine on progesteroneinduced contractions, as shown by the representative myograph of six myographs obtained from experiments in which myometrial strips were pretreated for $15 \mathrm{~min}$ with verapamil $\left(5 \times 10^{-7} \mathrm{M}\right)$ or nifedipine $\left(10^{-7} \mathrm{M}\right)$, progesterone $\left(5 \times 10^{-6} \mathrm{M}\right)$ was added, and the strips were cotreated for $20 \mathrm{~min}$ with verapamil or nifedipine. (D) Time-dependent changes in the RRPA of progesterone-induced contractions in the verapamil- and nifedipine-pretreated groups. (E) Representative myograph upon progesterone $\left(5 \times 10^{-6} \mathrm{M}\right)$, FPL6417 $\left(10^{-7} \mathrm{M}\right)$, or the vehicle addition in high-KCl-induced contractions. Progesterone was added $5 \mathrm{~min}$ after the tonic contraction was induced by high KCl. FPL64176 or the vehicle was added 20 min after the addition of progesterone. (F) Time-dependent changes in the RRPA of high-KCl-induced contractions in the FPL64176 alone, vehicle alone, progesterone-FPL64176, and progesterone-vehicle groups.

\section{Discussion}

Uterine contractions are essential for parturition, and it has recently been reported that increased intrauterine pressure during early pregnancy is crucial for fetal morphogenesis [28]. Therefore, uterine contractions play an important role not only in parturition but, also, in early fetal development. Various hormones are known to affect the morphological and functional changes in the pregnant uterus, including responses to stimuli and relaxants during pregnancy. In this study, we found that natural steroid hormones, such as estradiol, testosterone, cortisol, and aldosterone, did not cause contractions in the resting myometrium when added sequentially at a concentration of $10^{-7} \mathrm{M}-10^{-4} \mathrm{M}$. Conversely, progesterone caused continuous and rhythmic contractions, similar to labor, at $5 \times 10^{-7} \mathrm{M}$. This is the first study to demonstrate that progesterone causes contractions at concentrations as low as $5 \times 10^{-7} \mathrm{M}$. The contractions increased in a concentration-dependent manner to a maximum at $5 \times 10^{-6} \mathrm{M}$; however, progesterone-induced contractions began to decrease at $10^{-5} \mathrm{M}$ and disappeared within $10 \mathrm{~min}$ at concentrations $>5 \times 10^{-5} \mathrm{M}$. 
Furthermore, we evaluated the effects of progesterone when administered in a single dose and found that progesterone caused continuous and rhythmic contractions within $10 \mathrm{~min}$ at $5 \times 10^{-7} \mathrm{M}$ and rapidly induced contractions at concentrations $>10^{-6} \mathrm{M}$, which increased in a time-dependent manner, peaking at $5 \times 10^{-6} \mathrm{M}$. However, at concentrations $>5 \times 10^{-5} \mathrm{M}$, early progesterone-induced contractions decreased within seconds and subsequently disappeared within minutes. Together, these results suggested that the resting myometrium responds to progesterone at concentrations of $5 \times 10^{-7} \mathrm{M}-10^{-5} \mathrm{M}$ by contracting rhythmically but reacts to progesterone at concentrations $>5 \times 10^{-5} \mathrm{M}$ and relaxes.

In addition to the stimulatory effect on contractile activity, progesterone enhanced oxytocin-induced contractions at $5 \times 10^{-7} \mathrm{M}-10^{-5} \mathrm{M}$; however, no further progesteronederived stimulation was observed beyond this, and oxytocin-induced contractions were inhibited by a progesterone concentration $>5 \times 10^{-5} \mathrm{M}$. Thus, progesterone appears to exert conflicting stimulatory and inhibitory effects on contractile activity in an oxytocincontracted myometrium, and this inhibitory effect may explain why contractions decreased in the resting myometrium at a concentration $>5 \times 10^{-5} \mathrm{M}$. Moreover, whether the nongenomic effects of progesterone are inhibitory $[13,14,17,25]$ or stimulatory $[18-21]$ has been fiercely debated. Our experimental results may provide a possible solution to this debate by demonstrating that progesterone exerts conflicting nongenomic effects that vary with its concentration. Unexpectedly, progesterone did not enhance high-KCl-induced tonic contractions; however, it inhibited contractions at concentrations of $5 \times 10^{-7} \mathrm{M}-10^{-4} \mathrm{M}$. This inhibitory effect was independent of tissue toxicity, as the myometrial response to high- $\mathrm{KCl}$ was recovered after the solution was replaced several times. Together, these results suggest that the stimulatory effect of progesterone in the resting and oxytocincontracted myometrium at concentrations of $5 \times 10^{-7} \mathrm{M}-10^{-5} \mathrm{M}$ is abolished during high-KCl-induced contractions, allowing its inhibitory effects to be imparted at concentrations as low as $5 \times 10^{-7} \mathrm{M}$. Thus, the stimulatory effect of progesterone may be dominant at concentrations of $5 \times 10^{-7} \mathrm{M}-10^{-5} \mathrm{M}$. The mechanism involved in the inhibitory effect of progesterone at high concentrations $\left(>5 \times 10^{-5} \mathrm{M}\right)$ may be explained as follows. Progesterone may interfere with the oxytocin/oxytocin receptor axis at high concentrations and inhibit contractions, because progesterone is known to combine with the oxytocin receptor. Additionally, the oxytocin/oxytocin receptor is known to increase intracellular $\mathrm{Ca}^{2+}$, which activates cytosolic phospholipase A2, stimulating the formation of arachidonate from membrane glycerophospholipids. The arachidonate is converted to prostaglandin by prostaglandin endoperoxide- $\mathrm{H}$ synthases- 1 and -2 . Thus, the oxytocin/oxytocin receptor is involved in prostaglandin synthesis [29]. Therefore, the inhibitory effect of progesterone at pharmacological concentrations may, in part, depend on its effects on the oxytocin/oxytocin receptor axis and prostaglandin synthesis.

Recently, it was reported that the inhibitory effect of progesterone $\left(10^{-8} \mathrm{M}-10^{-4} \mathrm{M}\right)$ on $\mathrm{KCl}$-induced contractions was negligible [30]. The authors evaluated whether progesterone inhibited $\mathrm{KCl}(25 \mathrm{mM})$-induced rhythmic contractions by using uterine ring tissue, which consists of longitudinal muscles and circular muscles, obtained from 22-day-pregnant Sprague Dawley rats. In contrast, we evaluated the inhibitory effect of progesterone on high- $\mathrm{KCl}(72.7 \mathrm{mM})$-induced tonic contractions using myometrial strips consisting of longitudinal muscles obtained from 20-day-pregnant Wistar rats. We used myometrial strips in our experiments, because the longitudinal muscles play a principal role in the evacuation of conceptus in the late stages of pregnancy. The different results between the two studies may be due to differences in the pregnant rats, sampled tissues, and concentrations of $\mathrm{KCl}$ used, as well as the type of contractions.

Progesterone is known to combine with nPR in the cytosol and translocate into the nucleus, where it modulates the gene expression [31]; therefore, progesterone is generally thought to act via genomic effects over a period of hours or days. However, the conflicting effects of progesterone observed in this study are thought to be nongenomic, as they occurred within seconds or minutes. Additionally, we found that RU486 did not block 
progesterone-induced contractions $\left(5 \times 10^{-6} \mathrm{M}\right)$ in the resting myometrium, early progesterone $\left(5 \times 10^{-5} \mathrm{M}\right)$-induced contractions, the subsequent disappearance of contractions, or the inhibitory effect of progesterone $\left(5 \times 10^{-6} \mathrm{M}\right)$ on high-KCl-induced contractions. These findings suggest that progesterone causes rapid and rhythmic myometrial contractions and inhibits high- $\mathrm{KCl}$-induced contractions via nongenomic pathways through different membrane receptors. Moreover, the nongenomic pathway involved in the stimulatory effects of progesterone may be disturbed in high-KCl-induced contractions.

A high $\mathrm{KCl}$ inhibits intracellular $\mathrm{K}^{+}$efflux via the $\mathrm{K}^{+}$channel, causing slight plasma membrane depolarization, which causes extracellular $\mathrm{Na}^{+}$influx via $\mathrm{Na}^{+}$channels. This $\mathrm{Na}^{+}$influx then enhances plasma membrane depolarization in smooth muscle cells to primarily activate VDCCs, which cause a $\mathrm{Ca}^{2+}$ influx and, thus, activate calmodulin. The activated calmodulin $\left(\mathrm{Ca}^{2+}\right.$-calmodulin) complex induces MLC phosphorylation via the MLC kinase and causes tonic contractions. Simultaneously, the oxytocin-oxytocin receptor couples with $\mathrm{G}_{\mathrm{q} / 11}$ proteins stimulate a phosphoinositide turnover and activate phospholipase $\mathrm{C}$, thus producing inositol triphosphate $\left(\mathrm{IP}_{3}\right)$ and diacylglycerol [32-34]. $\mathrm{IP}_{3}$ releases $\mathrm{Ca}^{2+}$ from intracellular stores via the $\mathrm{IP}_{3}$ receptor and causes a $\mathrm{Ca}^{2+}$ influx via VDCCs, which stimulates a further $\mathrm{Ca}^{2+}$ release from intracellular stores via the ryanodine receptor [35]. However, the intracellular $\mathrm{Ca}^{2+}$ concentration required to cause agonist-induced rhythmic contractions is lower than that in high-KCl-induced tonic contractions [36]. Diacylglycerol causes a $\mathrm{Ca}^{2+}$ influx via ROCCs [37-39] and protein kinase $\mathrm{C}$ activation, which inhibits the dephosphorylation of phosphorylated MLC by inactivating MLC phosphatase, thus inhibiting relaxation. After causing contractions, the intracellular $\mathrm{Ca}^{2+}$ levels are decreased by calcium pumps, calcium-dependent (sensitive) $\mathrm{K}^{+}$channels, voltage-dependent $\mathrm{K}^{+}$ channels, uptake into intracellular $\mathrm{Ca}^{2+}$ stores, and the inhibition of $\mathrm{Ca}^{2+}$ influx by refractory VDCCs. Consequently, decreased intracellular $\mathrm{Ca}^{2+}$ levels induce a reverse reaction in contractile pathways that relaxes contractions. These periodic increases and decreases in intracellular $\mathrm{Ca}^{2+}$ levels are known as calcium oscillations [40-42]; however, this process does not occur in high-KCl-induced tonic contractions. Nevertheless, changes in the intracellular levels of cations, including $\mathrm{Ca}^{2+}$, and/or the contractile pattern may be related to the different responses to progesterone during oxytocin-induced rhythmic contractions and high-KCl-induced tonic contractions.

In this study, we revealed that rapid and rhythmic progesterone-induced contractions were caused by an increase in intracellular $\mathrm{Ca}^{2+}$ levels via plasma membrane channels, as contractions did not occur in calcium-free PSS. In addition, these plasma membrane channels may have been L-type VDCCs, because the contractions were completely blocked by the pretreatment with verapamil and nifedipine, thus indicating that the putative L-type VDCCs play an important role in the stimulatory effect of progesterone on the resting myometrium. However, the underlying mechanisms in this pathway remain unclear. A high $\mathrm{KCl}$ is known to cause contractions mainly via L-type VDCCs, which are also involved in oxytocin-induced contractions. Therefore, it has been hypothesized that the inhibitory effect of progesterone involves the closing of conventional L-type VDCCs, because progesterone inhibits high- $\mathrm{KCl}$-induced contractions and the putative L-type VDCCs involved in progesterone-induced contractions are closed during high-KClinduced contractions when conventional L-type VDCCs are opened. This hypothesis is further supported by the following findings: (a) FPL64176 (an activator of L-type calcium channels) increased the high-KCl-induced contractions and repressed the inhibitory effect of progesterone during high-KCl-induced contractions. (b) Progesterone, which may exert a stimulatory effect via the putative L-type VDCC, could not increase the high-KCl-induced contractions, although oxytocin, which exerts a stimulatory effect via conventional L-type VDCCs, could increase the high-KCl-induced contractions (data not shown). Additionally, our findings suggest that FPL6417 is an activator of conventional L-type VDCCs.

These results suggest that progesterone increases intracellular $\mathrm{Ca}^{2+}$ levels by opening putative L-type VDCCs via nongenomic progesterone/membrane receptor pathways, resulting in an increased intracellular voltage that further increases the intracellular $\mathrm{Ca}^{2+}$ 
levels by opening conventional L-type VDCCs. Moreover, high intracellular $\mathrm{Ca}^{2+}$ levels are decreased by the refractoriness of putative L-type VDCCs to progesterone and/or the closing of conventional L-type VDCCs via a nongenomic pathway involving progesterone/other membrane receptors. In addition, the opening of putative L-type VDCCs may be faster than the closing conventional L-type VDCCs. Recently, mPR $\alpha$ has been suggested as a candidate membrane receptor involved in closing conventional L-type VDCCs, because it has been reported to be involved in decreasing intracellular $\mathrm{Ca}^{2+}$ in vascular smooth muscles [12].

VDCCs consist of $\alpha_{1}, \alpha_{2}, \beta$, and $\gamma$ subunits. The $\alpha_{1}$ subunit is encoded by 10 different Cav genes; possesses an electronic sensor and channel pores; and assists with functional classification (L-, P/Q-, N-, R-, and T-types) based on the electrophysiological and pharmacological properties [43]. The $\alpha_{1}$ subunits of L-type VDCCs can be subclassified as Cav1.1, $\mathrm{Ca}_{\mathrm{v}} 1.2, \mathrm{Ca}_{\mathrm{v}} 1.3$, or $\mathrm{Ca}_{\mathrm{v}} 1.4$ and are expressed in various tissues, including the skeletal muscle; heart, brain, and retina; and endocrine organs. $\mathrm{Ca}_{\mathrm{v}} 1.2$ is primarily expressed in smooth muscles and the myocardium and is involved in contractions. The $\alpha_{2} \delta, \beta$, and $\gamma$ subunits play important roles in regulating the expression, function, and intracellular localization of the $\alpha_{1}$ subunit [44]; therefore, their modulation may be involved in the conflicting nongenomic effects of progesterone. Thus, the subunits of the putative L-type VDCCs may be functionally and/or structurally different from those of conventional L-type VDCCs.

However, there may be another reason for these conflicting nongenomic effectsnamely, the stimulatory action caused by putative L-type VDCCs. In this study, we found that progesterone causes pregnant myometrial contractions at a concentration of $5 \times 10^{-7} \mathrm{M}$ via a nongenomic pathway. Consistently, recent studies have demonstrated that progesterone $\left(5 \times 10^{-7} \mathrm{M}\right)$ increases intracellular $\mathrm{Ca}^{2+}$ levels in the human sperm via a nongenomic pathway and thereby enhances sperm motility by a process known as hyperactivation $[45,46]$. It has been reported that the increase in intracellular $\mathrm{Ca}^{2+}$ levels in human sperm is caused by a specific VDCC known as the sperm-specific $\mathrm{Ca}^{2+}$ channel (CatSper), which is located in the main section of the flagellum [47-49]. Additionally, progesterone can activate the orphan progesterone-dependent lipid hydrolase $\alpha / \beta$ hydrolase domain-containing protein 2 , which is expressed at high levels in the sperm plasma membrane and depletes the endocannabinoid 2-arachidonoylglycerol (2AG) levels, which typically inhibits CatSper. Therefore, progesterone can prevent the inhibition of CatSper by decreasing the 2AG levels, thereby increasing the intracellular $\mathrm{Ca}^{2+}$ levels and inducing sperm hyperactivation [50]. These findings indicate the possibility that a myometriumspecific calcium channel exists that is involved in the stimulatory action of progesterone; however, this is unlikely to be CatSper itself, because we found that 2AG $\left(10^{-6} \mathrm{M}\right) \mathrm{did}$ not inhibit progesterone $\left(10^{-6} \mathrm{M}\right)$-induced contractions (data not shown). To date, no study has reported that a putative myometrium-specific calcium channel is involved in the increase of intracellular $\mathrm{Ca}^{2+}$ caused by progesterone in the pregnant myometrium; therefore, further studies are required to determine whether a putative myometrium-specific calcium channel is involved in mediating the stimulatory effect of progesterone on contractile activities.

In this study, we found conflicting nongenomic effects of progesterone on contractile activities in the pregnant myometrium. We showed that the stimulatory effect of progesterone was dominant at physiological concentrations and the inhibitory effect was dominant at pharmacological concentrations. However, progesterone inhibited high-KClinduced tonic contractions at physiological concentrations. These findings lead us to believe that the stimulatory effect may be involved in the onset of parturition in rats and humans having no withdrawal of progesterone in the late stage of pregnancy and that progesterone may prevent tonic contractions like excessive labor pain. However, our interpretation may be unacceptable to some doctors who retain the conventional view that progesterone decreases contractile activities, prevents premature labor, and maintains pregnancy. Therefore, to provide additional support and understanding of the conflicting nongenomic effects of progesterone, we need to investigate the modulation of the conflicting effects of progesterone during pregnancy. It will be interesting to determine whether 
progesterone shows the conflicting nongenomic effects in nonpregnant, early-pregnant, middle-pregnant, and puerperium myometrium through the action of putative and conventional VDCCs. Additionally, it will be interesting to determine whether estrogen has a nongenomic inhibitory effect on contractile activities and whether it can abolish the nongenomic stimulatory effect of progesterone during pregnancy. Previously, we reported that dydrogesterone, a derivative of retroprogesterone with a reversed three-dimensional structure, exhibited a nongenomic inhibitory effect on contractile activities in the rat and human pregnant myometrium [16]. Therefore, we are interested in the effect of dydrogesterone on progesterone-induced contractions and the efficacy of dydrogesterone on preventing premature labor via nongenomic pathways. Further investigation is needed to address the issues underlying the roles and mechanisms of the conflicting nongenomic effects of progesterone.

\section{Materials and Methods}

\subsection{Chemicals}

Progesterone, 17 $\beta$-estradiol, testosterone, cortisol, aldosterone, RU486, nifedipine, verapamil, FPL6417, and dimethyl sulfoxide (DMSO) were purchased from Sigma-Aldrich (St. Louis, State of Missouri, USA). Oxytocin was obtained from ASKA Pharmaceuticals (Tokyo, Japan). All chemicals were dissolved in DMSO.

\subsection{Animals}

Pregnant Wistar rats were obtained from the Oriental Bioservice Corporation (Kyoto, Japan) and housed under controlled conditions (12-h light/12-h dark cycle) with water and rat chow provided ad libitum. The rats used in this study were 12 weeks of age, and this was their first pregnancy. The vaginal plug confirmation date was defined as day 0 . All rats were euthanized on day 20 by $\mathrm{CO}_{2}$ inhalation, and the uterus was removed and used for experiments.

\subsection{Myometrium Preparation and Evaluation of Contractile Activity}

Myometrial strips were prepared from the dissected rat uterus, as described previously [51,52]. Each strip (width: 2 to $3 \mathrm{~mm}$, length: 10-15 mm) was attached to a holder under $1 \mathrm{~g}$ of resting tension, equilibrated for $30 \mathrm{~min}$ in PSS, and then repeatedly treated with a 72.7-mM KCl solution (high- $\mathrm{KCl}$ ) until the response stabilized. PSS contained 136.9-mM $\mathrm{NaCl}$, 5.4-mM KCl, 1.5- $\mathrm{mM} \mathrm{CaCl}_{2}, 1.0-\mathrm{mM} \mathrm{MgCl}_{2}, 23.8-\mathrm{mM} \mathrm{NaHCO}_{3}, 5.5-\mathrm{mM}$ glucose, and $0.01-\mathrm{mM}$ ethylenediaminetetraacetic acid. A solution with high $\mathrm{KCl}$ concentration was prepared by replacing $\mathrm{NaCl}$ with an equimolar quantity of $\mathrm{KCl}$. Calcium-free PSS was prepared without $\mathrm{CaCl}_{2}$. These solutions were saturated with a $95 \% \mathrm{O}_{2} / 5 \% \mathrm{CO}_{2}$ mixture at $37^{\circ} \mathrm{C}(\mathrm{pH}$ 7.4). After pretreatment with high $\mathrm{KCl}$, a steroid hormone or a vehicle (DMSO) was added, and the myometrial contractile activity was recorded isometrically using a force-displacement transducer (TB611T; Nihon Kohden, Tokyo, Japan) connected to a Model 3134 strain amplifier. Uterine strips in each experiment were prepared from the uterine tissue of one animal (one strip/one group), and the experiment was repeated six times on each individual rat. Data were analyzed using the Unique Acquisition software package (Microsoft Windows 7; Unique Medical, Tokyo, Japan).

\subsection{Effects of Progesterone and Other Steroid Hormones on the Resting Myometrium}

Myometrial strips were pretreated with high $\mathrm{KCl}$ for $10 \mathrm{~min}$, and the peak area of contractions was used as the reference area. Five minutes after high $\mathrm{KCl}$ was replaced with PSS, steroid hormones were added. First, we evaluated the effect of progesterone at $10^{-7} \mathrm{M}$ and then increased the concentration to $5 \times 10^{-7}, 10^{-6}, 5 \times 10^{-6}, 10^{-5}, 5 \times 10^{-5}$, and $10^{-4} \mathrm{M}$ every $10 \mathrm{~min}$. We also evaluated the effect of other steroid hormones, such as estradiol, testosterone, cortisol, and aldosterone, on the myometrium at the same concentrations as progesterone. The RRPA (steroid hormone-induced peak area for $10 \mathrm{~min} / \mathrm{KCl}$-induced peak area for $10 \mathrm{~min}$ ) was compared between the steroid hormone and vehicle groups. We 
evaluated the effects of a single application of progesterone on the myometrial response. Myometrial strips were pretreated with high $\mathrm{KCl}$ for $5 \mathrm{~min}$, and the peak area was defined as the reference area. Five minutes after high $\mathrm{KCl}$ was replaced with PSS, progesterone was added $\left(10^{-7}, 5 \times 10^{-7}, 10^{-6}, 5 \times 10^{-6}, 10^{-5}, 5 \times 10^{-5}\right.$, or $\left.10^{-4} \mathrm{M}\right)$. The myometrial response to progesterone at each concentration was observed for $20 \mathrm{~min}$, and the contractile activity was evaluated using the progesterone-induced peak area/ $\mathrm{KCl}$-induced peak area for $5 \mathrm{~min}$ at 5 -min intervals (-5-0, 0-5, 5-10, 10-15, and 15-20 $\mathrm{min}$ ).

\subsection{Effects of Progesterone on Oxytocin- and High-KCl-Induced Myometrial Contractions}

Myometrial strips were pretreated with high $\mathrm{KCl}$ for $10 \mathrm{~min}$, and the peak area was defined as the reference area. Five minutes after high $\mathrm{KCl}$ had been replaced with PSS, contractions were induced using oxytocin $(100 \mu \mathrm{unit} / \mathrm{mL})$ or high $\mathrm{KCl}$ and observed for $10 \mathrm{~min}$. Progesterone was then added to the PSS and high $\mathrm{KCl}$, and the concentrations were increased sequentially every $10 \mathrm{~min}$ from $10^{-7} \mathrm{M}$ to $5 \times 10^{-7}, 10^{-6}, 5 \times 10^{-6}, 10^{-5}$, $5 \times 10^{-5}$, and $10^{-4} \mathrm{M}$. An equivalent volume of DMSO was added to the vehicle group at the same time as progesterone. The RRPA was compared between the progesterone- and vehicle-treated groups.

\subsection{Effects of RU486 on Progesterone Action}

Myometrial strips were preloaded with high $\mathrm{KCl}$ for $5 \mathrm{~min}$, and the peak area was defined as the reference area. Quiescent myometrial strips were pretreated for $60 \mathrm{~min}$ with RU486 at $10^{-7} \mathrm{M}$, because this concentration has been reported to be sufficient for binding with $\mathrm{nPR}$, with a $\mathrm{K}_{\mathrm{d}}$ value of $3.6 \times 10^{-9} \mathrm{M}$ [53]. Progesterone $\left(5 \times 10^{-6}\right.$ or $\left.5 \times 10^{-5} \mathrm{M}\right)$ was then added, and the effect of RU486 on the action of progesterone was observed for $20 \mathrm{~min}$. Contractions were also induced in the RU486-pretreated myometrial strips using high $\mathrm{KCl}$ to evaluate the effect of RU486 on the action of progesterone $\left(5 \times 10^{-6} \mathrm{M}\right)$ during agonist-induced contractions for $20 \mathrm{~min}$. In the vehicle group, myometrial strips were pretreated with an equivalent volume of DMSO for $60 \mathrm{~min}$. The effect of RU486 on the action of progesterone was evaluated using the relative RRPA at 5-min intervals $(-5-0,0-5,5-10,10-15$, and 15-20 min). The RRPA was compared between the RU486 and vehicle groups.

\subsection{Effects of Calcium-Free PSS and Calcium Channel Inhibitors on Progesterone in the Quiescent Myometrium}

Myometrial strips were preloaded with high $\mathrm{KCl}$ for $5 \mathrm{~min}$, and the peak area was used as the reference area. Five minutes after high $\mathrm{KCl}$ was replaced with PSS and calcium-free PSS, progesterone $\left(5 \times 10^{-6} \mathrm{M}\right)$ was added to each solution, and the contractile response was observed for $20 \mathrm{~min}$. Similarly, myometrial strips were pretreated with verapamil $\left(5 \times 10^{-7} \mathrm{M}\right)$ and nifedipine $\left(10^{-7} \mathrm{M}\right)$ for $15 \mathrm{~min}$ in PSS before progesterone $\left(5 \times 10^{-6} \mathrm{M}\right)$ was added, and the contractile response was observed for $20 \mathrm{~min}$ and evaluated using the RRPA at 5-min intervals (-5-0, 0-5, 5-10, 10-15, and 15-20 min).

\subsection{Effects of Calcium Channel Activator on Progesterone during High-KCl-Induced Contractions}

The myometrial strips were divided into four groups: progesterone + FPL64176, progesterone + vehicle, vehicle alone, and FPL64176 alone. The myometrial strips were preloaded with high $\mathrm{KCl}$ for $5 \mathrm{~min}$, and the peak area was used as the reference area. Five minutes after high $\mathrm{KCl}$ was replaced with PSS, contractions were induced in the myometrial strips using high $\mathrm{KCl}$. Progesterone $\left(5 \times 10^{-6} \mathrm{M}\right)$, FPL64176 $\left(10^{-7} \mathrm{M}\right)$, and DMSO were added to the appropriate groups, and the contractions were observed for $20 \mathrm{~min}$. The RRPA of high-KCl-induced contractions were evaluated in all groups at more-than 5-min intervals $(-5-0,0-5,5-10,10-15,15-20,20-25,25-30,30-35$, and $35-40 \mathrm{~min})$. 


\subsection{Statistical Analysis}

Data were expressed as the mean \pm standard deviation (SD) and were analyzed using JMP version 10.0.2 (SAS Institute, Cary, NC, USA). The statistical significance of differences in the measured parameters across different groups was assessed using the Steel-Dwass test for multiple comparisons or the Wilcoxon rank-sum test. Results were considered statistically significant at $p$-values $<0.05$.

\section{Conclusions}

We conclude that progesterone exerts conflicting nongenomic effects on the pregnant the myometrium, with stimulatory and inhibitory effects on contractile activities. Additionally, we conclude that the stimulatory effect occurs faster and is more significant than the inhibitory effect in the resting myometrium. However, the dominant stimulatory effect is abolished by a high $\mathrm{KCl}$, and the recessive inhibitory effect is highlighted. The stimulatory effect may be caused via the putative L-type VDCC or myometrium-specific VDCC, whereas the inhibitory effect may be caused via the conventional L-type VDCC that is involved in high- $\mathrm{KCl}$ - and oxytocin-induced contractions. An improved understanding of the nongenomic stimulatory and inhibitory effects of progesterone, and further studies on the mechanisms of the progesterone-membrane receptor-calcium channel axis could help modulate parturition and treat preterm birth.

Supplementary Materials: The following are available online at https:/ /www.mdpi.com/1422-006 7/22/4/2154/s1. Figure S1: Experimental measuring system and evaluation of hormone-induced contractions. (A) A myometrial strip attached to a holder under 1-g resting tension in a Magnus tube filled with physiological saline solution (PSS). The contractile activity was recorded using a forcedisplacement transducer connected to a strain amplifier and analyzed using the Unique Acquisition software package. (B) Representative pattern of high-KCl-induced contractions and hormone-induced contractions. The high-KCl-induced peak areas for 5 or $10 \mathrm{~min}$ were defined as the reference areas. Contractile activity, including tension, frequency, and contractile time were evaluated as the relative ratio of the peak area (RRPA: hormone-induced peak area/high-KCl-induced peak area), because the absolute values of the peak areas varied between the individual strips, even when prepared from the same uterine tissue. Table S1: Relative ratio of the peak areas of natural steroid hormone-induced contractions. Table S2: Relative ratio of the peak areas of progesterone-induced contractions at various concentrations. Table S3: Relative ratio of the peak areas of oxytocin-induced contractions and high-KCl-induced contractions in the progesterone and vehicle groups. Table S4: Relative ratio of the peak areas of progesterone-induced contractions and high-KCl-induced contractions in the RU486 and vehicle groups. Table S5: Relative ratio of the peak areas of progesterone-induced contractions under the treatments with a physiological saline solution (PSS) or calcium-free PSS and in the vehicle-pretreatment, verapamil-pretreatment, and nifedipine-pretreatment groups. Table S6: Relative ratio of the peak areas of high-KCl-induced contractions in the vehicle, FPL64176, $\mathrm{P}_{4}+$ vehicle, and $\mathrm{P}_{4}+$ FPL64176 groups.

Author Contributions: Conceptualization, K.Y.; methodology, K.Y.; validation, K.Y., A.Y., and H.O.; formal analysis, A.Y.; investigation, K.Y. and A.Y.; data curation, A.Y.; writing—original draft preparation, K.Y.; and writing-review and editing, K.Y., A.Y., and H.O. All authors have read and agreed to the published version of the manuscript.

Funding: This work was supported by research grant D2 (2020) from Kansai Medical University.

Institutional Review Board Statement: All animal experiments were performed according to the Guide for the Care and Use of Laboratory Animals prepared by Kansai Medical University (Osaka, Japan), and these procedures were approved by the Institutional Animal Care and Use Committee of Kansai Medical University (protocol code: 19-014 and date of approval: 8 May 2019).

Informed Consent Statement: Not applicable.

Data Availability Statement: All data are included in the article. 
Acknowledgments: The authors thank Yumi Kouno and Yukako Yamawaki for their administrative assistance.

Conflicts of Interest: The authors declare no conflict of interest.

\section{References}

1. Csapo, A.I.; Corner, G.W. The antagonistic effects of estrogen and progesterone on the staircase phenomenon in uterine muscle. Endocrinology 1952, 51, 378-385. [CrossRef]

2. Corner, G.W.; Csapo, A. Action of the ovarian hormones on uterine muscle. Br. Med. J. 1953, 1, 687-693. [CrossRef] [PubMed]

3. Fuchs, A.R.; Periyasamy, S.; Alexandrova, M.; Soloff, M.S. Correlation between oxytocin receptor concentration and responsiveness to oxytocin in pregnant rat myometrium: Effects of ovarian steroids. Endocrinology 1983, 113, 742-749. [CrossRef] [PubMed]

4. Murone, C.; Chai, S.Y.; Müller-Esterl, W.; Mendelsohn, F.A.; Clements, J. Localization of bradykinin B2 receptors in the endometrium and myometrium of rat uterus and the effects of estrogen and progesterone. Endocrinology 1999, 140, 3372-3382. [CrossRef] [PubMed]

5. Engstrom, T.; Bratholm, P.; Christensen, N.J.; Vilhardt, H. Up-regulation of oxytocin receptors in non-pregnant rat myometrium by isoproterenol: Effects of steroids. J. Endocrinol. 1999, 161, 403-411. [CrossRef]

6. Romero, R.; Yeo, L.; Miranda, J.; Hassan, S.S.; Conde-Agudelo, A.; Chaiworapongsa, T. A blueprint for the prevention of preterm birth: Vaginal progesterone in women with a short cervix. J. Perinat. Med. 2013, 41, 27-44. [CrossRef]

7. Lewis, D.F.; Baker, S.L.; Stauffer, R. Short cervix and vaginal progesterone: A model on how to tackle the problem of idiopathic preterm labor. J. Reprod. Med. 2013, 58, 434-437.

8. Society for Maternal-Fetal Medicine Publications Committee, with assistance of Vincenzo Berghella. Progesterone and preterm birth prevention: Translating clinical trials data into clinical practice. Am. J. Obstet. Gynecol. 2012, 206, 376-386. [CrossRef]

9. American College of Obstetricians and Gynecologists. ACOG Committee on Practice Bulletins, Obstetrics, prediction and prevention of preterm birth. Obstet. Gynecol. 2012, 120, 964-973. [CrossRef]

10. Iams, J.D. Prevention of preterm parturition. N. Engl. J. Med. 2014, 370, 254-261. [CrossRef]

11. Ichida, S.; Moriyama, M.; Terao, M. Characteristics of Ca influxes through voltage- and receptor-operated Ca channels in uterine smooth muscle. J. Pharmacol. Exp. Ther. 1984, 228, 439-445.

12. Edwards, D.; Good, D.M.; Granger, S.E.; Hollingsworth, M.; Robson, A.; Small, R.C.; Weston, A.H. The spasmogenic action of oxytocin in the rat uterus-comparison with other agonists. Br. J. Pharmacol. 1986, 88, 899-908. [CrossRef] [PubMed]

13. Perusquía, M.; García-Yañez, E.; Ibáñez, R.; Kubli-Garfias, C. Non-genomic mechanism of action of delta-4 and 5-reduced androgens and progestins on the contractility of the isolated rat myometrium. Life Sci. 1990, 47, 1547-1553. [CrossRef]

14. Perusquía, M.; Villalón, C.M. The relaxant effect of sex steroids in rat myometrium is independent of the gamma-amino butyric acid system. Life Sci. 1996, 58, 913-926. [CrossRef]

15. Hidalgo, A.; Suzano, R.C.; Revuelta, M.P.; Sanchez-Diaz, C.; Baamonde, A.; Cantabrana, B. Calcium and depolarization-dependent effect of pregnenolone derivatives on uterine smooth muscle. Gen. Pharmacol. 1996, 27, 879-885. [CrossRef]

16. Yasuda, K.; Sumi, G.I.; Murata, H.; Kida, N.; Kido, T.; Okada, H. The steroid hormone dydrogesterone inhibits myometrial contraction independently of the progesterone/progesterone receptor pathway. Life Sci. 2018, 207, 508-515. [CrossRef]

17. Pang, Y.; Thomas, P. Role of $\mathrm{mPR} \alpha$ (PAQR7) in progesterone-induced $\mathrm{Ca}^{2+}$ decrease in human vascular smooth muscle cells. J. Mol. Endocrinol. 2019, 63, 199-213. [CrossRef]

18. Karteris, E.; Zervou, S.; Pang, Y.; Dong, J.; Hillhouse, E.W.; Randeva, H.S.; Thomas, P. Progesterone signaling in human myometrium through two novel membrane $G$ protein-coupled receptors: Potential role in functional progesterone withdrawal at term. Mol. Endocrinol. 2006, 20, 1519-1534. [CrossRef]

19. Fu, X.; Rezapour, M.; Löfgren, M.; Ulmsten, U.; Bäckström, T. Unexpected stimulatory effect of progesterone on human myometrial contractile activity in vitro. Obstet. Gynecol. 1993, 82, 23-28.

20. Löfgren, M.; Bäckström, T. Continuous progesterone exposure associated with high contraction frequency in human term myometrial strips. Acta. Obstet. Gynecol. Scand. 1994, 73, 186-191. [CrossRef]

21. Rezapour, M.; Hongpaisan, J.; Fu, X.; Bäckström, T.; Roomans, G.M.; Ulmsten, U. Effects of progesterone and oxytocin on intracellular elemental composition of term human myometrium in vitro. Eur. J. Obstet. Gynecol. Reprod. Biol. 1996, 68, 191-197. [CrossRef]

22. Hardy, D.B.; Janowski, B.A.; Corey, D.R.; Mendelson, C.R. Progesterone receptor plays a major antiinflammatory role in human myometrial cells by antagonism of nuclear factor-KB activation of cyclooxygenase 2 expression. Mol. Endocrinol. 2006, 20, 2724-2733. [CrossRef] [PubMed]

23. Tan, H.; Yi, L.; Rote, N.S.; Hurd, W.W.; Mesiano, S. Progesterone receptor-A and -B have opposite effects on proinflammatory gene expression in human myometrial cells: Implications for progesterone actions in human pregnancy and parturition. J. Clin. Endocrinol. Metab. 2012, 97, E719-E730. [CrossRef]

24. Pepe, G.J.; Rothchild, I. A comparative study of serum progesterone levels in pregnancy and in various types of pseudopregnancy in the rat. Endocrinology 1974, 95, 275-279. [CrossRef]

25. Grazzini, E.; Guillon, G.; Mouillac, B.; Zingg, H.H. Inhibition of oxytocin receptor function by direct binding of progesterone. Nature. 1998, 392, 509-512. [CrossRef] 
26. Rampe, D.; Dage, R.C. Functional interactions between two Ca2+ channel activators, (S)-Bay K 8644 and FPL 64176 , in smooth muscle. Mol. Pharmacol. 1992, 41, 599-602.

27. Liwang, L.; Gonzalez, P.K.; Barrett, C.F.; Rittenhouse, A.R. The calcium channel ligand FPL 64176 enhances L-type but inhibits N-type neuronal calcium currents. Neuropharmacology 2003, 45, 281-292.

28. Ueda, Y.; Kimura-Yoshida, C.; Mochida, K.; Tsume, M.; Kameo, Y.; Adachi, T.; Lefebvre, O.; Hiramatsu, R.; Matsuo, I. Intrauterine pressures adjusted by Reichert's membrane are crucial for early mouse morphogenesis. Cell Rep. 2020, 31, 107637. [CrossRef]

29. Fuchs, A.R.; Fuchs, F. Endocrinology of human parturition: A review. Br. J. Obstet. Gynaecol. 1984, 91, 948-967. [CrossRef]

30. Mirdamadi, M.; Kothencz, A.; Szúcs, E.; Benyhe, S.; Szécsi, M.; Gáspár, R. Non-genomic actions of sex hormones on pregnant uterine contractility in rats: An in vitro study at term. Life Sci. 2020, 263, 118584. [CrossRef]

31. Patel, B.; Elguero, S.; Thakore, S.; Dahoud, W.; Bedaiwy, M.; Mesiano, S. Role of nuclear progesterone receptor isoforms in uterine pathophysiology. Hum. Reprod. Update 2015, 21, 155-173. [CrossRef]

32. Ruzycky, A.L.; Crankshaw, D.J. Role of inositol phospholipid hydrolysis in the initiation of agonist-induced contractions of rat uterus: Effects of domination by 17 beta-estradiol and progesterone. Can. J. Physiol. Pharmacol. 1988, 66, 10-17. [CrossRef] [PubMed]

33. Schrey, M.P.; Cornford, P.A.; Read, A.M.; Steer, P.J. A role for phosphoinositide hydrolysis in human uterine smooth muscle during parturition. Am. J. Obstet. Gynecol. 1988, 159, 964-970. [CrossRef]

34. Molnár, M.; Hertelendy, F. Regulation of intracellular free calcium in human myometrial cells by prostaglandin F2 alpha: Comparison with oxytocin. J. Clin. Endocrinol. Metab. 1990, 71, 1243-1250. [CrossRef] [PubMed]

35. Berridge, M.J. Smooth muscle cell calcium activation mechanisms. J. Physiol. 2008, 586, 5047-5061. [CrossRef]

36. Somlyo, A.P.; Wu, X.; Walker, L.A.; Somlyo, A.V. Pharmacomechanical coupling: The role of calcium, G-proteins, kinases and phosphatases. Rev. Physiol. Biochem. Pharmacol. 1999, 134, 201-234.

37. Zhuge, R.; Li, S.; Chen, T.H.; Hsu, W.H. Oxytocin induced a biphasic increase in the intracellular Ca ${ }^{2+}$ concentration of porcine myometrial cells: Participation of a pertussis toxin-insensitive G-protein, inositol 1,4,5-trisphosphate-sensitive $\mathrm{Ca}^{2+}$ pool, and $\mathrm{Ca}^{2+}$ channels. Mol. Reprod. Dev. 1995, 41, 20-28. [CrossRef]

38. Shlykov, S.G.; Sanborn, B.M. Stimulation of intracellular Ca2+ oscillations by diacylglycerol in human myometrial cells. Cell Calcium 2004, 36, 157-164. [CrossRef]

39. Large, W.A. Receptor-operated Ca2(+)-permeable nonselective cation channels in vascular smooth muscle: A physiologic perspective. J. Cardiovasc. Electrophysiol. 2002, 13, 493-501. [CrossRef]

40. Woods, N.M.; Cuthbertson, K.S.; Cobbold, P.H. Repetitive transient rises in cytoplasmic free calcium in hormone-stimulated hepatocytes. Nature 1986, 319, 600-602. [CrossRef]

41. Berridge, M.J. Inositol trisphosphate and calcium signaling. Nature 1993, 361, 315-325. [CrossRef]

42. Iino, M.; Kasai, H.; Yamazawa, T. Visualization of neural control of intracellular Ca2+ concentration in single vascular smooth muscle cells in situ. EMBO J. 1994, 13, 5026-5031. [CrossRef] [PubMed]

43. Catterall, W.A. Voltage-gated calcium channels. Cold Spring Harb. Perspect. Biol. 2011, 3, a003947. [CrossRef] [PubMed]

44. Tanabe, T.; Takeshima, H.; Mikami, A.; Flockerzi, V.; Takahashi, H.; Kangawa, K.; Kojima, M.; Matsuo, H.; Hirose, T.; Numa, S. Primary structure of the receptor for calcium channel blockers from skeletal muscle. Nature 1987, 328, 313-318. [CrossRef]

45. Lishko, P.V.; Botchkina, I.L.; Kirichok, Y. Progesterone activates the principal Ca ${ }^{2+}$ channel of human sperm. Nature 2011, 471, 387-391. [CrossRef] [PubMed]

46. Smith, J.F.; Syritsyna, O.; Fellous, M.; Serres, C.; Mannowetz, N.; Kirichok, Y.; Lishko, P.V. Disruption of the principal, progesteroneactivated sperm Ca2+ channel in a CatSper2-deficient infertile patient. Proc. Natl. Acad. Sci. USA 2013, 110, 6823-6828. [CrossRef] [PubMed]

47. Quill, T.A.; Ren, D.; Clapham, D.E.; Garbers, D.L. A voltage-gated ion channel expressed specifically in spermatozoa. Proc. Natl. Acad. Sci. USA 2001, 98, 12527-12531. [CrossRef]

48. Ren, D.; Navarro, B.; Perez, G.; Jackson, A.C.; Hsu, S.; Shi, Q.; Tilly, J.L.; Clapham, D.E. A sperm ion channel required for sperm motility and male fertility. Nature 2001, 413, 603-609. [CrossRef]

49. Carlson, A.E.; Westenbroek, R.E.; Quill, T.; Ren, D.; Clapham, D.E.; Hille, B.; Garbers, D.L.; Babcock, D.F. CatSper1 required for evoked $\mathrm{Ca}^{2+}$ entry and control of flagellar function in sperm. Proc. Natl. Acad. Sci. USA 2003, 10, 14864-14868. [CrossRef]

50. Miller, M.R.; Mannowetz, N.; Iavarone, A.T.; Safavi, R.; Gracheva, E.O.; Smith, J.F.; Hill, R.Z.; Bautista, D.M.; Kirichok, Y.; Lishko, P.V. Unconventional endocannabinoid signaling governs sperm activation via the sex hormone progesterone. Science 2016, 352, 555-559. [CrossRef]

51. Egawa, M.; Yasuda, K.; Nakajima, T.; Okada, H.; Yoshimura, T.; Yuri, T.; Yasuhara, M.; Nakamoto, T.; Nagata, F.; Kanzaki, H. Smoking enhances oxytocin-induced rhythmic myometrial contraction. Biol. Reprod. 2003, 68, 2274-2280. [CrossRef] [PubMed]

52. Yasuda, K.; Nakamoto, T.; Yasuhara, M.; Okada, H.; Nakajima, T.; Kanzaki, H.; Hori, M.; Ozaki, H. Role of protein kinase C beta in rhythmic contractions of human pregnant myometrium. Reproduction 2007, 133, 797-806. [CrossRef]

53. Hurd, C.; Moudgil, V.K. Characterization of R5020 and RU486 binding to progesterone receptor from calf uterus. Biochemistry 1998, 27, 3618-3623. [CrossRef] [PubMed] 